\title{
Optimal management of multiple sclerosis during pregnancy: current perspectives
}

This article was published in the following Dove Press journal:

Degenerative Neurological and Neuromuscular Disease

5 August 2014

Number of times this article has been viewed

\author{
Nadja Borisow \\ Friedemann Paul \\ Jan Dörr \\ NeuroCure Clinical Research \\ Center and Clinical and \\ Experimental Research Center \\ for Multiple Sclerosis, Charité - \\ Universitätsmedizin Berlin, Berlin, \\ Germany
}

Correspondence: Nadja Borisow NeuroCure Clinical Research Center, Charité - Universitätsmedizin Berlin, Charitéplatz I, I0II7 Berlin, Germany Tel +4930450539040

$\mathrm{Fax}+4930450539915$

Emailnadja.borisow@charite.de
Abstract: Multiple sclerosis (MS) is a common inflammatory demyelinating disorder of the central nervous system. It frequently affects females in their reproductive phase of life. Therefore, family planning, pregnancy, and breastfeeding are important issues in the management of MS, particularly with respect to counseling and drug treatment. This paper reviews currently available data on the outcome of pregnancies in MS patients and the influence of pregnancy on the course of the disease. We give an update on the use of various disease-modifying MS drugs during pregnancy and breastfeeding. In addition to established therapies such as interferon- $\beta$, glatiramer acetate, natalizumab, and fingolimod, we also discuss the state of knowledge about new agents such as dimethyl fumarate, teriflunomide, and alemtuzumab in the context of pregnancy and breastfeeding.

Keywords: multiple sclerosis, pregnancy, lactation, disease-modifying therapy

\section{Introduction}

Multiple sclerosis (MS) is the most common chronic inflammatory disorder of the central nervous system during young adulthood. ${ }^{1}$ Simplified infiltration of autoreactive lymphocytes leads to the formation of inflammatory plaques in the brain and spinal cord characterized by demyelination and neurodegeneration, which result in transient neurologic dysfunction. Thereafter, diffuse axonal and neuroaxonal degeneration leads to an ongoing accumulation of neurologic deficits. Both genetic and environmental factors are considered to be involved in the pathogenesis of MS. ${ }^{1}$ Women are more frequently affected than men. In some regions, especially in countries of northern latitude, the male to female ratio is as high as 1:4.5..$^{2-4}$ Because many MS patients are of fertile age, family planning and pregnancy can become relevant issues during the disease course.

Reasonably, many women with MS who plan to conceive or are already pregnant consult their obstetrician for advice. Unfortunately, obstetricians are not usually experienced in MS. Conversely, many neurologists have only limited knowledge of obstetrics and pregnancy in MS. ${ }^{5}$ For this reason, it may be difficult for MS patients to get competent advice on the influence of MS on pregnancy, birth, and lactation, or on the effect of pregnancy on the MS disease course.

This paper summarizes current knowledge on the influence of pregnancy and lactation on MS and addresses the question of whether having MS influences the course and outcome of pregnancy. In particular, we give an overview of current recommendations on the use of disease-modifying drugs (DMDs) during pregnancy and lactation. 
Further pregnancy-related issues, such as inheritance risk, fertility, and reproduction techniques, are beyond the scope of this paper and are addressed elsewhere. ${ }^{6,7}$

\section{Influence of pregnancy on MS}

Numerous studies have investigated the influence of pregnancy on the MS disease course. In 1998, the PRIMS (Pregnancy in Multiple Sclerosis) study examined the course of 269 pregnancies in $254 \mathrm{MS}$ patients in a prospective manner. ${ }^{8}$ The authors showed that the relapse rate decreases during pregnancy and reaches a nadir in the third trimester. However, in the first months after delivery, the relapse rate increased to a higher level than before pregnancy. Six to 9 months after delivery, the relapse rate decreased to prepregnancy rates. Further studies subsequently confirmed these results. ${ }^{9,10}$ Whether relapses in the year before and during pregnancy represent a risk factor for postpartum relapse is not yet conclusive. ${ }^{11,12}$

The immunologic mechanisms responsible for the decrease in disease activity during pregnancy are still poorly understood. It is supposed that immunologic changes aimed at protecting the fetus from maternal immune defense contribute to the observed reduction in disease activity. A T-helper 1 to T-helper 2 cell shift is often discussed in the literature, ${ }^{13,14}$ although current data suggest that the mechanisms are more complex. Changes in CD56 $6^{\text {bright }}$ natural killer cells, ${ }^{14}$ interferon gamma (IFN- $\gamma$ )-producing CD4+ T-cells, ${ }^{15}$ in the CD4+/CD8+-ratio, ${ }^{16}$ and in interleukin-8 serum levels ${ }^{17}$ have been described during pregnancy. Moreover, regulatory T-cells seem to play an important role in modulating disease activity during pregnancy in MS. ${ }^{18-21}$ Further studies are necessary to investigate the underlying cellular and molecular mechanisms.

\section{Influence of MS on pregnancy and childbirth}

Many female MS patients are concerned that the disease may have a negative impact on pregnancy or childbirth. In 2011, a meta-analysis evaluated the results of 22 studies between 1983 and 2009, and included a total of more than 13,000 pregnancies in mothers with MS. ${ }^{22}$ The rates of abortion, prematurity, malformation, and neonatal death in MS patients were comparable with those in healthy mothers. Although some surveys revealed a slight reduction in birth weight of between $108 \mathrm{~g}$ and $123 \mathrm{~g},{ }^{23,24}$ an elevated risk of low birth weight $(<2,500 \mathrm{~g})$ in newborns of MS mothers was not detected in the meta-analysis. ${ }^{22}$ Another survey studying 432 births in $321 \mathrm{MS}$ patients showed no differences in birth weight, mean gestational age, labor duration, or 5-minute
Apgar score. ${ }^{25}$ Except for a higher rate of maternal anemia, no other pregnancy-related complications, including gestational diabetes mellitus or preeclampsia, were recorded. ${ }^{26}$

In healthy women, rates of primary cesarean section in various countries show great variability and are influenced by religious, social, and cultural values. It is therefore not surprising that cesarean delivery in MS mothers shows wide regional differences, ranging from $10 \%$ to $40 \%{ }^{22}$ Some studies found no elevated rates of cesarean section in MS, ${ }^{25,26}$ whereas others revealed a higher rate of cesarean delivery when compared with the general population. ${ }^{23,27}$ Importantly, the higher rate of cesarean section in MS was due to an increase in planned and not emergency deliveries. ${ }^{23}$

On the one hand, a cesarean section may in fact be beneficial because it can be performed electively; there is no pain during childbirth, and the risks of retained placenta and urinary incontinence are lower. On the other hand, a cesarean delivery carries a greater risk of injury to the uterus, bladder, or ureter, and longer hospitalization. Many MS patients and physicians may favor a cesarean section as they are concerned that spasticity, neuromuscular perineal weakness, or exhaustion in the context of MS could complicate a natural delivery. In rare cases, these may actually be reasons for planning an elective cesarean section. However, given that the number of emergency cesarean sections in MS does not exceed that in healthy women, the fact alone of suffering from MS should not, in our opinion, be a reason to choose cesarean section over vaginal delivery if no other obstetric reasons exist.

Some surveys have revealed higher rates of operative delivery with the use of forceps or vacuum extraction in MS patients ${ }^{23,26,28}$ due to exhaustion and slow progression of delivery. MS patients should therefore be informed about these issues. In 1998, Confavreux et al found no impact of epidural analgesia on the postpartum relapse rate in $\mathrm{MS}^{8}$ Another study in 2012 confirmed these results. ${ }^{29} \mathrm{MS}$ patients should therefore be advised that MS per se is no reason to abstain from epidural analgesia.

\section{Disease-modifying drugs during pregnancy}

Over approximately 25 years, an increasing number of drugs have been made available for immunomodulatory therapy in MS. The most experience is with interferon beta (IFN- $\beta$ ) and glatiramer acetate (GA), which are administered subcutaneously. In patients with adverse effects or high disease activity, escalation with intravenous natalizumab once a month or orally administered fingolimod, a sphingosine receptor modulator, is feasible. For patients with secondary 
progressive MS, mitoxantrone is a possible treatment option. Recently, teriflunomide, dimethyl fumarate (DMF), and alemtuzumab have been made available as further therapy options in relapsing-remitting MS.

Managing DMDs in the context of conception and pregnancy poses a challenge for both MS patients and attending physicians. On the one hand, unnecessary risks to the child should be avoided; on the other, patients left without medication are subject to a higher risk of MS relapse. To date, none of the DMDs available for MS has been approved for use during pregnancy. The current data are primarily derived from MS pregnancy registries and are often collected retrospectively. Therefore, it is difficult to give evidence-based recommendations for MS treatment during pregnancy. The United States Food and Drug Administration (FDA) pregnancy categories can be used as a reference for decision-making (Table 1). According to that classification, GA is considered to be the safest of the currently available MS drugs. It is assigned to category B, whereas IFN- $\beta$, natalizumab, and fingolimod are classified one category lower. We describe in detail below the data currently available for the different drugs and their use during pregnancy.

\section{Intravenous methylprednisolone}

Relapses in MS are commonly treated with high-dose methylprednisolone given intravenously on 3-5 consecutive days. Glucocorticoid therapy accelerates recovery, but does not seem to have an impact on the level of remission finally achieved. ${ }^{30}$

Methylprednisolone is classified within category $\mathrm{C}$ by the FDA (Table 1). The manufacturers indicate that during pregnancy, especially in the first trimester, methylprednisolone should be used only after a thorough risk-benefit analysis. Animal studies showed higher risks of cleft palates and intrauterine growth disturbances. Adequate studies in human pregnancy are lacking.

An elevated risk of oral clefts has been described in pregnant women suffering from inflammatory bowel disease, bronchial asthma, or lupus erythematosus who were given glucocorticoids during the first trimester. ${ }^{31}$ Another study showed lower gestational age, decreased birth weight, and higher rates of miscarriage after exposure to glucocorticoids in the first trimester. ${ }^{32}$ In light of these findings, we recommend discussing the use of glucocorticoids during the first 3 months of pregnancy very critically. Use of such medication during this period should be reserved for severe MS relapses. Treatment with glucocorticoids during the second and third trimesters does not seem to be harmful to the fetus. ${ }^{33}$

\section{Interferon beta}

Since the mid-1990s, IFN- $\beta$ has been approved for subcutaneous or intramuscular immunomodulatory therapy of MS. IFN- $\beta$ leads to a reduction in relapse rate of approximately

Table I US Food and Drug Administration pregnancy categories

\begin{tabular}{|c|c|c|}
\hline $\begin{array}{l}\text { FDA pregnancy } \\
\text { category }\end{array}$ & Description & Drug \\
\hline$B$ & $\begin{array}{l}\text { Animal studies have revealed no evidence of harm to the fetus; however, there are no adequate } \\
\text { and well controlled studies in pregnant women. } \\
\text { OR } \\
\text { Animal studies have shown an adverse effect, but adequate and well controlled studies in pregnant } \\
\text { women have failed to demonstrate a risk to the fetus in any trimester. }\end{array}$ & Glatiramer acetate \\
\hline C & $\begin{array}{l}\text { Animal studies have shown an adverse effect and there are no adequate and well controlled studies } \\
\text { in pregnant women. } \\
\text { OR } \\
\text { No animal studies have been conducted and there are no adequate and well-controlled studies } \\
\text { in pregnant women. }\end{array}$ & $\begin{array}{l}\text { IFN- } \beta \\
\text { Natalizumab } \\
\text { Fingolimod } \\
\text { Dexamethasone } \\
\text { Prednisolone } \\
\text { IVIG } \\
\text { Dimethyl fumarate } \\
\text { Cyclosporin A }\end{array}$ \\
\hline$D$ & $\begin{array}{l}\text { Adequate well controlled or observational studies in pregnant women have demonstrated a risk to the } \\
\text { fetus. However, the benefits of therapy may outweigh the potential risk. For example, the drug may be } \\
\text { acceptable if needed in a life-threatening situation or serious disease for which safer drugs cannot be } \\
\text { used or are ineffective. }\end{array}$ & $\begin{array}{l}\text { Cyclophosphamide } \\
\text { Azathioprine } \\
\text { Mitoxantrone }\end{array}$ \\
\hline$X$ & $\begin{array}{l}\text { Adequate well controlled or observational studies in animals or pregnant women have demonstrated } \\
\text { positive evidence of fetal abnormalities or risks. The use of the product is contraindicated in women } \\
\text { who are or may become pregnant. }\end{array}$ & $\begin{array}{l}\text { Methotrexate } \\
\text { Teriflunomide }\end{array}$ \\
\hline
\end{tabular}

Abbreviations: IVIG, intravenous immunoglobulin G; FDA, US Food and Drug Administration; IFN- $\beta$, interferon beta. 
$30 \%{ }^{34}$ and decreases the progression of disability in longterm follow-up. ${ }^{35}$

The FDA classifies IFN- $\beta$ within category $C$ because animal studies have shown adverse effects on the fetus, and no adequate studies in pregnant women exist (Table 1). According to the German manufacturing information, it is explicitly contraindicated to start IFN- $\beta$ therapy during pregnancy due to a potentially elevated risk of spontaneous abortion. Patients with a high relapse rate who are already undergoing treatment with IFN- $\beta$ are advised to weigh the risk of severe relapse after discontinuation of IFN- $\beta$ against the risk of spontaneous abortion.

Currently, IFN- $\beta$ can be considered the DMD with the largest experience of use in pregnant women with MS. In the literature, data from approximately 1,000 pregnancies with IFN- $\beta$ exposure at the time of conception and at least the first weeks of pregnancy are currently available. Table 2 provides an overview of a number of studies on birth outcome after exposure to IFN- $\beta$. In 2012, a systematic review by Lu et al summarized the results of several studies on the safety of DMDs during pregnancy. ${ }^{36} \mathrm{~A}$ total of 761 pregnancies with
IFN- $\beta$ exposure were included. The authors associated IFN- $\beta$ exposure with preterm birth as well as lower birth weight and length. However, no elevated risks of spontaneous abortion, birth weight under 2,500 g, cesarean section, or congenital abnormalities were described.

Some authors, including $\mathrm{Lu}$ et al, ${ }^{35,36}$ advise women to discontinue DMD when they plan to conceive. In contrast, Schröder and Schilli point out that since June 2006 an IFN- $\beta$ treatment-free interval before a planned pregnancy is no longer recommended by the European Medicines Agency. ${ }^{37}$ Based on the data currently available, intake of IFN- $\beta$ during the conception period and the first weeks of pregnancy seems to be relatively safe. It has become increasingly common to continue IFN- $\beta$ until pregnancy has been confirmed. Given that it is not known when gestation will start, this approach seems to be justified, particularly in patients with high disease activity. However, continuation of IFN- $\beta$ treatment throughout pregnancy should be considered very carefully. Only a small number of cases involving IFN- $\beta$ therapy over the course of the entire pregnancy is available in the current literature. ${ }^{38,39}$ In these studies, all

Table 2 Studies on birth outcome after exposure to interferon beta

\begin{tabular}{|c|c|c|c|}
\hline Year & Authors & Pregnancies (n) & Results \\
\hline 2005 & Boskovic et a ${ }^{84}$ & 23 & $\begin{array}{l}\text { Increased rate of spontaneous abortion }(39 \%) \text {; decreased birth weight }(\sim 3,190 \mathrm{~g}) \text {; } \\
\text { two major birth defects (Down syndrome, } X \text { chromosome abnormality) }\end{array}$ \\
\hline 2005 & $\begin{array}{l}\text { Sandberg- } \\
\text { Wollheim et } \mathrm{al}^{85}\end{array}$ & 41 & Normal spontaneous abortion rate, one birth defect (hydrocephalus) \\
\hline 2008 & Patti et a ${ }^{86}$ & 14 & $\begin{array}{l}\text { Normal spontaneous abortion rate; normal birth weight; shorter gestational period } \\
\text { ( } 37.8 \text { weeks), no malformations }\end{array}$ \\
\hline 2009 & Hellwig et $\mathrm{al}^{87}$ & 17 & Normal miscarriage rate (I $2 \%)$, normal birth weight \\
\hline 2009 & $\begin{array}{l}\text { Weber-Schoendorfer } \\
\text { and Schaefer }{ }^{44}\end{array}$ & 69 & $\begin{array}{l}\text { Higher rate of spontaneous abortion for IFN- } \beta \text { Ib }(28 \%) \text { compared with IFN- } \beta \text { Ia }(5 \%) \text { but } \\
\text { normal spontaneous abortion rate in combined IFN- } \beta \text { cohort; lower birth weight }(\sim 2,330 \mathrm{~g})\end{array}$ \\
\hline 2010 & Amato et $a^{88}$ & 88 & $\begin{array}{l}\text { Lower birth weight }(\sim 3,000 \mathrm{~g}) \text {; decreased birth length }(\sim 49 \mathrm{~cm}) \text {; higher rate of preterm } \\
\text { delivery ( } 33 \% \text { versus } 20 \%) \text {; normal rate of spontaneous abortion; no major birth defects }\end{array}$ \\
\hline 2010 & Coyle et $\mathrm{a}^{89}$ & 69 & $\begin{array}{l}\text { Normal spontaneous abortion rate; three birth defects (trisomy } 2 \text { I, multiple hemangiomas, } \\
\text { cardiovascular defect, and hip dysplasia) }\end{array}$ \\
\hline 2011 & $\begin{array}{l}\text { Sandberg- } \\
\text { Wollheim et al90 }\end{array}$ & 425 & $\begin{array}{l}\text { Normal spontaneous abortion rate; three major birth defects (VACTERL syndrome, } \\
\text { Tetralogy of Fallot, solitary kidney) }\end{array}$ \\
\hline 2011 & Finkelsztejn et al ${ }^{10}$ & 69 & $\begin{array}{l}\text { One case of delayed intrauterine growth; two malformations (Dandy-Walker-syndrome, } \\
\text { ventriculomegaly); two cases of neonatal jaundice }\end{array}$ \\
\hline 2011 & Hellwig and Gold ${ }^{38}$ & 7 & $\begin{array}{l}\text { Exposure throughout pregnancy; normal birth weight; no preterm delivery; } \\
\text { one malformation (valvular stenosis of pulmonary artery) }\end{array}$ \\
\hline 2012 & Lu et $\mathrm{al}^{48}$ & 15 & $\begin{array}{l}\text { Trend to higher risk for assisted vaginal delivery; normal rate of cesarean section; } \\
\text { normal birth weight gestational age and Apgar score; no congenital abnormalities }\end{array}$ \\
\hline 2012 & Richman et al ${ }^{91}$ & 298 & 30 spontaneous abortions; 27 birth defects (no details given) \\
\hline 2012 & Hellwig et $a^{50}$ & 78 & $\begin{array}{l}\text { Normal birth weight and length; three birth defects (ventricular septal defect, valvular } \\
\text { stenosis of the pulmonary artery, hip dysplasia) }\end{array}$ \\
\hline 2013 & Fragoso et $\mathrm{al}^{49}$ & 17 & $\begin{array}{l}\text { Normal rate of obstetric complications; lower birth weight }(\sim 2,760 \mathrm{~g}) \text { and length }(\sim 47 \mathrm{~cm}) \text {; } \\
\text { lower postpartum relapse rate and EDSS progression in women with }>8 \text { weeks of exposure } \\
\text { during pregnancy }\end{array}$ \\
\hline 2014 & Dung and $\mathrm{Panda}^{39}$ & I & Exposure throughout pregnancy; normal birth weight; no congenital anomaly \\
\hline
\end{tabular}

Abbreviations: EDSS, Expanded Disability Status Scale; IFN, interferon; VACTERL, Vertebral anomalies, Anal atresia, Cardiac defects, Tracheoesophageal fistula and/or Esophageal atresia, Renal \& Radial anomalies and Limb defects. 
patients delivered newborns of normal birth weight and gestational age. However, one baby had valvular stenosis of the pulmonary artery. The causal relationship between this malformation and intrauterine IFN- $\beta$ exposure is not clear. Obviously, these data are not sufficient to make any therapy recommendations.

\section{Glatiramer acetate}

GA was approved in 1996 as a DMD for relapsing-remitting MS in the USA, and European Union approval was granted 5 years later. GA reduces the MS relapse rate by approximately $30 \% 0^{40}$ and the number of enhancing magnetic resonance imaging (MRI) lesions to the same extent. ${ }^{41}$ Moreover, a $45 \%$ risk reduction in conversion from clinically isolated syndrome to clinically definite MS was reported in the PreCISe study (ClinicalTrials.gov identifier NCT00666224). ${ }^{42}$

According to the FDA classification (Table 1), GA is considered the safest DMD during pregnancy in MS. This classification is based on there being no evidence of fetal harm in animal studies, although adequate and well controlled studies in pregnant women are lacking. Compared with IFN- $\beta$, considerably fewer studies exist with respect to safety during pregnancy. In the pivotal clinical trials and post-marketing period until 2003, 250 pregnancies were recorded. The rates of spontaneous abortions and major congenital anomalies were described to be in the range of the general population. ${ }^{43}$ In addition, approximately 200 pregnancies under treatment with GA are described in the literature. These studies revealed a normal spontaneous abortion rate, ${ }^{44-47}$ mean birth weight, ${ }^{10,44-50}$ and gestational age. ${ }^{10,44,47,48,50}$ Some studies, however, described preterm delivery, ${ }^{38}$ one case of neonatal death, ${ }^{49}$ and a reduction in birth weight ${ }^{38}$ and length. ${ }^{49}$ Reported congenital anomalies were, for example, penile hypospadias, ${ }^{38}$ clubfoot, ${ }^{44}$ atrioventricular canal defects, ${ }^{44}$ bone malformations, ${ }^{49}$ abnormality of urinary bladder valves,${ }^{50}$ and hip dysplasia. ${ }^{50}$ However, the number, severity, and nature of congenital malformations did not exceed the range expected in the general population.

Whether GA should be discontinued before a planned conception is controversial in the literature. In light of the limited data, some authors recommend discontinuation as soon as conception is planned, ${ }^{36}$ whereas others caution against leaving patients untreated while waiting for conception. $^{51}$

In line with most expert opinion and guidelines, and similar to the approach with IFN- $\beta$, we recommend patients continue treatment with GA until pregnancy has been confirmed, particularly in patients with a high relapse rate before pregnancy.
In any case, the possible risks and benefits have to be weighed individually, taking into account the viewpoint of the patient and lack of available data at present.

\section{Natalizumab}

Natalizumab is a monoclonal antibody used in the treatment of MS patients with high disease activity and those in whom IFN- $\beta$ or GA has had an insufficient effect. Studies have shown a reduction in the annualized relapse rate of up to two thirds ${ }^{52,53}$ and a significant reduction in gadoliniumenhancing lesions. ${ }^{53,54}$

The largest data collection on pregnancy outcome after exposure to natalizumab comes from the Tysabri ${ }^{\circledR}$ (natalizumab) Pregnancy Exposure Registry. ${ }^{55}$ More than 350 pregnancies with exposure to natalizumab within 90 days prior to the last menstrual period were followed. In 28 of these pregnancies, major and/or minor birth defects were observed, which is comparable with the rate detected by active birth registries in the general population. ${ }^{56}$ The rate of spontaneous abortion corresponded to the frequency in the general population.

Apart from this registry, approximately 40 patients receiving treatment with natalizumab during pregnancy are described in the literature. ${ }^{57-60}$ In two of the studies, natalizumab was continued until the third trimester or even throughout the pregnancy. ${ }^{59,60}$ These studies reported normal rates of spontaneous abortion and congenital malformation, and normal birth weight and length. Another case report described normal Apgar score, birth weight and length, and head circumference in two newborns with mothers who took natalizumab until week 34 of pregnancy. ${ }^{61}$ However, a reduction in CXCL12-induced T-cell chemotaxis was found in both of these children, which might compromise the neonatal immune system and be associated with an increased risk of infection.

Compared with IFN- $\beta$ and GA, it is even more difficult to give advice about treatment with natalizumab in the context of a planned pregnancy. On the one hand, until now, there has been no conclusive evidence for an increased risk of adverse pregnancy outcomes. Moreover, discontinuation of natalizumab in the context of a planned pregnancy carries the risk of a rebound of disease activity. ${ }^{62}$ On the other hand, the data currently available are insufficient to rule out rare complications. Therefore, treatment with natalizumab should be stopped at the latest when pregnancy has been detected. After carefully assessing the potential risks and benefits, continuing treatment around the time of conception or even pregnancy can be taken into consideration. In contrast with 
IFN- $\beta$, the manufacturer of natalizumab does not rule out use of the drug during pregnancy when necessary due to the clinical condition of the patient.

\section{Fingolimod}

Fingolimod acts as a sphingosine receptor modulator and has been approved for highly active relapsing-remitting MS in Europe since March 2011. Compared with placebo, it leads to a decrease in the annualized relapse rate of more than $50 \%$ and significantly reduces the number of gadoliniumenhancing lesions seen on MRI. ${ }^{63}$ In animal studies, fingolimod showed teratogenic effects, with increased rates of visceral malformation, eg, persisting truncus arteriosus or ventricular septal defect. Further, fetal growth retardation and an increase in embryofetal mortality were observed. For this reason, the manufacturer's information advises against becoming pregnant during and for up to 2 months following treatment with fingolimod, and to stop fingolimod therapy immediately when an unplanned pregnancy is detected.

The outcomes of 127 pregnancies from the clinical trials and post-marketing experience of fingolimod were presented at the European Committee for Treatment and Research in Multiple Sclerosis meeting in October 2012.64 In these pregnancies, 21 spontaneous and 40 induced abortions were reported. Five congenital anomalies and three other pregnancy abnormalities occurred. This corresponds to the expected frequency in the general population. Out of this cohort, 66 pregnancies with in utero exposure to fingolimod are currently published. ${ }^{65}$ To collect further data, a multinational fingolimod pregnancy registry has been established.

\section{Mitoxantrone}

Mitoxantrone is an intercalating agent that leads to disturbances in DNA synthesis and repair mechanisms. It is approved in Europe for progressive relapsing and secondary progressive MS. Mitoxantrone therapy may result in improvements of disability, changes in the ambulation index, and a reduction in the number of treated relapses. ${ }^{66}$

Mitoxantrone is known to be mutagenic. The FDA classifies mitoxantrone within category $\mathrm{D}$ because of the known risks to the fetus, but in individual cases the potential benefit may outweigh the risk. The manufacturer's information indicates that in the event of an unplanned pregnancy during treatment with mitoxantrone, genetic counseling should be provided. In the literature, two case reports describe the pregnancy outcome after in utero exposure to mitoxantrone in MS patients. ${ }^{67,68}$ In one case, restricted growth without evidence of congenital malformation was reported.$^{67}$ The other study described a newborn with Pierre Robin sequence, a congenital malformation with cleft palate, micrognathia, and glossoptosis attributable to mitoxantrone exposure. ${ }^{68}$ Both males and females are advised to wait at least 6 months after discontinuing mitoxantrone therapy before starting unprotected sexual intercourse. Moreover, before beginning treatment, male MS patients should be informed about the possibility of cryopreserving sperm.

\section{Teriflunomide}

Teriflunomide is another drug available for oral use in MS therapy. Teriflunomide is the active metabolite of leflunomide, and is used as a disease-modifying antirheumatic drug. By inhibiting mitochondrial dihydroorotate dehydrogenase, teriflunomide inhibits the de novo synthesis of pyrimidine and thus reduces cell proliferation. This results in a decrease in numbers of activated lymphocytes and leads to a reduction in MRI gadolinium-enhancing lesions and annualized relapse rate by nearly $30 \%{ }^{69}$

For leflunomide, which has structural similarities to teriflunomide, a study involving 64 pregnant women with rheumatoid arthritis showed no elevated risk of congenital malformation, preterm delivery, or reduction in birth weight. ${ }^{70}$ Although teriflunomide has shown no negative effects on fertility in animal studies, there is evidence of reproductive toxicity. The only existing data on pregnancy outcomes in humans come from the global pharmacovigilance database held by the manufacturer. In that database, 83 pregnancies in female patients and 22 pregnancies in partners of male patients were recorded. ${ }^{71}$ These pregnancies were detected during participation in teriflunomide clinical trials. The authors report 29 induced and 13 spontaneous abortions in female patients. Among partners of teriflunomide-treated males, two induced abortions and one spontaneous abortion were described. No congenital malformations were observed, and birth weight and gestational age were within the normal range.

The manufacturer recommends a reliable method of contraception during treatment with teriflunomide and as long as the plasma level is higher than $0.02 \mathrm{mg} / \mathrm{L}$. If an unplanned pregnancy occurs during treatment, accelerated elimination of teriflunomide by cholestyramine or charcoal is strongly advised. Due to the long half-life, it might otherwise take between 8 months and 2 years after stopping teriflunomide for the plasma level to reach values below $0.02 \mathrm{mg} / \mathrm{L}$. The extent to which this approach actually reduces the risk of an adverse pregnancy outcome is not yet known.

In MS patients who are planning pregnancy, use of teriflunomide should be discontinued and the plasma 
level assessed. If necessary, the teriflunomide level can be reduced by the measures mentioned above before starting unprotected sexual intercourse. If the plasma level is below $0.02 \mathrm{mg} / \mathrm{L}$ in two measurements within an interval of 2 weeks, and a further safety interval of one and a half months is maintained thereafter, there should be no risk to the newborn.

\section{Dimethyl fumarate}

In February 2014, DMF was approved as a further oral MS drug in Europe. DMF reduces the annualized relapse rate by approximately $50 \%$ and leads to a significant decrease in contrast-enhancing lesions on MRI. ${ }^{55}$ The manufacturer's information describes that, in animal studies, high doses of DMF led to fetal growth restriction and increased lethality, although fertility does not seem to be reduced. The outcome of 25 pregnancies in humans undergoing DMF therapy was presented at the 2013 annual meeting of the American Academy of Neurology. ${ }^{72}$ No increase in rates of spontaneous abortion or fetal malformation were reported. However, given that existing safety data are insufficient, DMF is not recommended for use during pregnancy.

\section{Alemtuzumab}

Alemtuzumab is a recombinant monoclonal antibody directed against CD52 on the cell surface of $\mathrm{T}$ and $\mathrm{B}$ lymphocytes. Alemtuzumab mediates immunosuppressive effects by depletion and repopulation of white blood cells. Compared with IFN- $\beta$, it leads to a significant reduction in annualized relapse rates and contrast-enhancing MRI lesions. ${ }^{73,74}$ With an interval of 1 year alemtuzumab is given on 5 and 3 consecutive days, respectively, followed by a mandatory safety monitoring period of 48 months. Animal pregnancy studies showed a significant reduction in the number of viable fetuses and a higher number of animals with intrauterine deaths due to administration of alemtuzumab during pregnancy. Moreover, lower weight gain during gestation was observed.

The manufacturer indicates that within 30 days after each alemtuzumab treatment cycle, serum levels were low or even not detectable. However, females of childbearing age are advised to avoid pregnancy during and 4 months after each treatment period, because alemtuzumab is known to cross the placenta barrier. Data on pregnancies occurring during clinical trials have not yet been published by the manufacturer.

\section{Breastfeeding in MS}

There is still insufficient knowledge on whether breastfeeding influences the course of MS, and postpartum relapse rate in particular. The results of several studies have been quite controversial, in some cases showing protective effects ${ }^{75-77}$ and in other cases showing no effects. ${ }^{8,78,79}$ A meta-analysis of 12 studies revealed a positive effect of breastfeeding on the relapse rate, although many factors may contribute to a bias in those studies. ${ }^{80}$ Some studies were carried out retrospectively; moreover, in some, nursing women already had a lower annualized relapse rate before pregnancy and were less frequently treated with DMD compared with patients who were not breastfeeding. In any event, the risk of postpartum relapse during lactation always has to be weighed critically against starting treatment with a DMD soon after delivery. In patients with a high risk of relapse, waiving DMD in favor of breastfeeding has to be considered carefully, whereas in patients with low disease activity it may be justifiable.

\section{Medication for MS during lactation}

None of the DMDs mentioned above has been approved for treatment of MS during lactation. Methylprednisolone is known to pass into breast milk. For this reason, many women are advised to wean their child when receiving glucocorticoids for treatment of relapses. Nevertheless, there is a tendency to continue nursing despite cortisone therapy. If an interval of 4 hours between medication and breastfeeding is maintained, this approach seems to be reasonable. ${ }^{33}$ IFN- $\beta$ and GA might be the safest DMDs to use during lactation because they have a high molecular weight and are not detectable to a relevant extent in breast milk. ${ }^{81}$ Natalizumab, fingolimod, and mitoxantrone are known to pass into breast milk and should not be used by breastfeeding women. Animal studies have shown that teriflunomide and alemtuzumab pass into breast milk; for DMF there is no information on that issue available.

\section{Fatherhood in patients with MS}

Little is known about the course and outcome of pregnancies fathered by men with MS. In 2010, the first study on pregnancy outcomes in MS fathers receiving diseasemodifying therapy (DMT) was published by Hellwig et al. ${ }^{82}$ Compared with healthy mothers and MS mothers with and without DMT, no differences were found in birth weight and length. Recently, Lu et al published data on 202 pregnancies fathered by 141 men with MS. ${ }^{83}$ There were no differences in mean birth weight and gestational age compared with fathers without MS. Bearing in mind the lack of data, it seems reasonable for male MS patients to continue DMT during the conception period. Only treatment with mitoxantrone, as mentioned above, should be stopped 6 months before pregnancy. 


\section{Conclusion}

Managing MS medication is a challenge, particularly when patients are pregnant or breastfeeding. For drugs that have been available for decades, such as IFN- $\beta$ and GA, there is an increasing amount of information from pregnancy registries and observational studies. For new medications, such as DMF or teriflunomide, significantly less data are available. Therefore, further documentation in pregnancy registries of (unplanned) pregnancies with in utero exposure to DMDs is urgently needed. Attending physicians need to stay informed about current findings in MS pregnancy studies to be able to provide their patients with individual counseling based on the current state of knowledge.

\section{Disclosure}

The authors report no conflicts of interest in this work.

\section{References}

1. Compston A, Coles A. Multiple sclerosis. Lancet. 2008;372(9648): 1502-1517.

2. Trojano M, Lucchese G, Graziano G, et al; MS Base Study Group and the New Zealand MS Prevalence Study Group. Geographical variations in sex ratio trends over time in multiple sclerosis. PLoS One. 2012;7(10):e48078.

3. Chancellor AM, Addidle M, Dawson K. Multiple sclerosis is more prevalent in northern New Zealand than previously reported. Intern Med J. 2003;33(3):79-83.

4. Orton SM, Herrera BM, Yee IM, et al. Sex ratio of multiple sclerosis in Canada: a longitudinal study. Lancet Neurol. 2006;5(11):932-936.

5. Borisow N, Paul F, Ohlraun S, Pach D, Fischer F, Dörr J. Pregnancy in multiple sclerosis: a questionnaire study. PLoS One. 2014;9(6):e99106.

6. Borisow N, Döring A, Pfueller CF, Paul F, Dörr J, Hellwig K. Expert recommendations to personalization of medical approaches in treatment of multiple sclerosis: an overview of family planning and pregnancy. EPMA J. 2012;3(1):9.

7. McCombe PA, Greer JM. Female reproductive issues in multiple sclerosis. Mult Scler. 2013;19(4):392-402.

8. Confavreux C, Hutchinson M, Hours MM, Cortinovis-Tourniaire P, Moreau T. Rate of pregnancy-related relapse in multiple sclerosis. Pregnancy in Multiple Sclerosis Group. N Engl J Med. 1998;339(5): 285-291.

9. Salemi G, Callari G, Gammino M, et al. The relapse rate of multiple sclerosis changes during pregnancy: a cohort study. Acta Neurol Scand. 2004;110(1):23-26.

10. Finkelsztejn A, Fragoso YD, Ferreira MLB, et al. The Brazilian database on pregnancy in multiple sclerosis. Clin Neurol Neurosurg. 2011;113(4):277-280.

11. Vukusic S, Hutchinson M, Hours M, et al. Pregnancy and multiple sclerosis (the PRIMS study): clinical predictors of post-partum relapse. Brain. 2004;127 Pt 6:1353-1360.

12. Neuteboom RF, Janssens AC, Siepman TA, et al. Pregnancy in multiple sclerosis: clinical and self-report scales. J Neurol. 2012;259(2): 311-317.

13. Al-Shammri S, Rawoot P, Azizieh F, et al. Th1/Th2 cytokine patterns and clinical profiles during and after pregnancy in women with multiple sclerosis. J Neurol Sci. 2004;222(1-2):21-27.

14. Airas L, Saraste M, Rinta S, Huang YH, Wiendl H; Finnish Multiple Sclerosis and Pregnancy Study Group. Immunoregulatory factors in multiple sclerosis patients during and after pregnancy: relevance of natural killer cells. Clin Exp Immunol. 2008;151(2):235-243.
15. Langer-Gould A, Gupta R, Huang S, et al. Interferon-gamma-producing T cells, pregnancy, and postpartum relapses of multiple sclerosis. Arch Neurol. 2010;67(1):51-57.

16. Saraste M, Väisänen S, Alanen A, Airas L; Finnish Multiple Sclerosis and Pregnancy Study Group. Clinical and immunologic evaluation of women with multiple sclerosis during and after pregnancy. Gend Med. 2007;4(1):45-55.

17. Neuteboom RF, Verbraak E, Voerman JS, et al. First trimester interleukin 8 levels are associated with postpartum relapse in multiple sclerosis. Mult Scler. 2009;15(11):1356-1358.

18. Somerset DA, Zheng Y, Kilby MD, Sansom DM, Drayson MT. Normal human pregnancy is associated with an elevation in the immune suppressive CD25+ CD4+ regulatory T-cell subset. Immunology. 2004; 112(1):38-43.

19. Santner-Nanan B, Peek MJ, Khanam R, et al. Systemic increase in the ratio between Foxp3+ and IL-17-producing CD4+ T cells in healthy pregnancy but not in preeclampsia. J Immunol. 2009;183(11): 7023-7030.

20. Sánchez-Ramón S, Navarro AJ, Aristimuño C, et al. Pregnancy-induced expansion of regulatory T-lymphocytes may mediate protection to multiple sclerosis activity. Immunol Lett. 2005;96(2):195-201.

21. Neuteboom RF, Verbraak E, Wierenga-Wolf AF, et al. Pregnancyinduced fluctuations in functional T-cell subsets in multiple sclerosis patients. Mult Scler. 2010;16(9):1073-1078.

22. Finkelsztejn A, Brooks JB, Paschoal FM Jr, Fragoso YD. What can we really tell women with multiple sclerosis regarding pregnancy? A systematic review and meta-analysis of the literature. BJOG. 2011;118(7): 790-797.

23. Dahl J, Myhr KM, Daltveit AK, Hoff JM, Gilhus NE. Pregnancy, delivery, and birth outcome in women with multiple sclerosis. Neurology. 2005;65(12):1961-1963.

24. Dahl J, Myhr KM, Daltveit AK, Gilhus NE. Planned vaginal births in women with multiple sclerosis: delivery and birth outcome. Acta Neurol Scand Suppl. 2006;183:51-54.

25. Van der Kop ML, Pearce MS, Dahlgren L, et al. Neonatal and delivery outcomes in women with multiple sclerosis. Ann Neurol. 2011;70(1): 41-50.

26. Mueller BA, Zhang J, Critchlow CW. Birth outcomes and need for hospitalization after delivery among women with multiple sclerosis. Am J Obstet Gynecol. 2002;186(3):446-452.

27. Kelly VM, Nelson LM, Chakravarty EF. Obstetric outcomes in women with multiple sclerosis and epilepsy. Neurology. 2009;73(22): 1831-1836.

28. Jalkanen A, Alanen A, Airas L. Pregnancy outcome in women with multiple sclerosis: results from a prospective nationwide study in Finland. Mult Scler. 2010;16(8):950-955.

29. Pastò L, Portaccio E, Ghezzi A, et al. Epidural analgesia and cesarean delivery in multiple sclerosis post-partum relapses: the Italian cohort study. BMC Neurol. 2012;12:165.

30. Beck RW, Cleary PA. Optic neuritis treatment trial. One-year follow-up results. Arch Ophthalmol. 1993;111(6):773-775.

31. Park-Wyllie L, Mazzotta P, PastuszakA, et al. Birth defects after maternal exposure to corticosteroids: prospective cohort study and meta-analysis of epidemiological studies. Teratology. 2000;62(6):385-392.

32. Gur C, Diav-Citrin O, Shechtman S, Arnon J, Ornoy A. Pregnancy outcome after first trimester exposure to corticosteroids: a prospective controlled study. Reprod Toxicol. 2004;18(1):93-101.

33. Ferrero S, Pretta S, Ragni N. Multiple sclerosis: management issues during pregnancy. Eur J Obstet Gynecol Reprod Biol. 2004;115(1):3-9.

34. [No authors listed]. Interferon beta-1b in the treatment of multiple sclerosis: final outcome of the randomized controlled trial. The IFNB Multiple Sclerosis Study Group and The University of British Columbia MS/MRI Analysis Group. Neurology. 1995;45(7):1277-1285.

35. Bermel RA, Weinstock-Guttman B, Bourdette D, Foulds P, You X, Rudick RA. Intramuscular interferon beta-1a therapy in patients with relapsing-remitting multiple sclerosis: a 15-year follow-up study. Mult Scler. 2010;16(5):588-596. 
36. Lu E, Wang BW, Guimond C, Synnes A, Sadovnick D, Tremlett H. Disease-modifying drugs for multiple sclerosis in pregnancy: a systematic review. Neurology. 2012;79(11):1130-1135.

37. Schröder S, Schilli M. ["Other circumstances": on the contribution by Hoffmann LA, Kümpfel T, Heer I, et al. “Other circumstances”: Pregnancy and immunomodulatory therapy in multiple sclerosis. Nervenarzt. 2006;77:663-670]. Nervenarzt. 2006;77(12):1519. German.

38. Hellwig K, Gold R. Glatiramer acetate and interferon-beta throughout gestation and postpartum in women with multiple sclerosis. $J$ Neurol. 2011;258(3):502-503.

39. Dung AA, Panda AK. Interferon $\beta$-1a therapy for multiple sclerosis during pregnancy: an unresolved issue. BMJ Case Rep. April 7, 2014. [Epub ahead of print.]

40. Johnson KP, Brooks BR, Cohen JA, et al. Extended use of glatiramer acetate (Copaxone) is well tolerated and maintains its clinical effect on multiple sclerosis relapse rate and degree of disability. Copolymer 1 Multiple Sclerosis Study Group. Neurology. 1998;50(3):701-708.

41. Comi G, Filippi M, Wolinsky JS. European/Canadian multicenter, double-blind, randomized, placebo-controlled study of the effects of glatiramer acetate on magnetic resonance imaging - measured disease activity and burden in patients with relapsing multiple sclerosis. European/Canadian Glatiramer Acetate Study Group. Ann Neurol. 2001;49(3):290-297.

42. Comi G, Martinelli V, Rodegher M, et al; PreCISE Study Group Effect of glatiramer acetate on conversion to clinically definite multiple sclerosis in patients with clinically isolated syndrome (PreCISe study): a randomised, double-blind, placebo-controlled trial. Lancet. 2009;374(9700):1503-1511.

43. Coyle P, Johnson KP, Pardo L, Stark Y. Pregnancy outcomes in patients with multiple sclerosis treated with glatiramer acetate (Copaxone). Mult Scler. 2003;9 Suppl 1:S1-S153.

44. Weber-Schoendorfer C, Schaefer C. Multiple sclerosis, immunomodulators, and pregnancy outcome: a prospective observational study. Mult Scler. 2009;15(9):1037-1042.

45. Salminen HJ, Leggett H, Boggild M. Glatiramer acetate exposure in pregnancy: preliminary safety and birth outcomes. J Neurol. 2010;257(12):2020-2023.

46. Fragoso YD, Finkelsztejn A, Kaimen-Maciel DR, et al. Long-term use of glatiramer acetate by 11 pregnant women with multiple sclerosis: a retrospective, multicentre case series. CNS Drugs. 2010;24(11):969-976.

47. Giannini M, Portaccio E, Ghezzi A, et al. Pregnancy and fetal outcomes after glatiramer acetate exposure in patients with multiple sclerosis: a prospective observational multicentric study. BMC Neurol. 2012;12:124.

48. Lu E, Dahlgren L, Sadovnick A, Sayao A, Synnes A, Tremlett H. Perinatal outcomes in women with multiple sclerosis exposed to diseasemodifying drugs. Mult Scler. 2012;18(4):460-467.

49. Fragoso YD, Boggild M, Macias-Islas MA, et al. The effects of longterm exposure to disease-modifying drugs during pregnancy in multiple sclerosis. Clin Neurol Neurosurg. 2013;115(2):154-159.

50. Hellwig K, Haghikia A, Rockhoff M, Gold R. Multiple sclerosis and pregnancy: experience from a nationwide database in Germany. Ther Adv Neurol Disord. 2012;5(5):247-253.

51. Charles JA, Tremlett H, Lu E, Guimond C, Sadovnick AD. Diseasemodifying drugs for multiple sclerosis in pregnancy: a systematic review. Neurology. 2013;80(11):1068-1069.

52. Miller DH, Khan OA, Sheremata WA, et al. A controlled trial of natalizumab for relapsing multiple sclerosis. $N$ Engl J Med. 2003;348(1): 15-23.

53. Polman CH, O’Connor PW, Havrdova E, et al. A randomized, placebocontrolled trial of natalizumab for relapsing multiple sclerosis. $N$ Engl J Med. 2006;354(9):899-910.

54. Havrdova E, Galetta S, Hutchinson M, et al. Effect of natalizumab on clinical and radiological disease activity in multiple sclerosis: a retrospective analysis of the Natalizumab Safety and Efficacy in Relapsing-Remitting Multiple Sclerosis (AFFIRM) study. Lancet Neurol. 2009;8(3):254-260.
55. Cristiano L, Friend S, Bozic C, Bloomgren G. Evaluation of pregnancy outcomes from the TYSABRI ${ }^{\circledR}$ (natalizumab) Pregnancy Exposure Registry (P02.127). Available from: http://www.neurology.org/cgi/ content/meeting_abstract/80/1_MeetingAbstracts/P02.127. Accessed June 20, 2014

56. Queißer-Luft A, Stolz G, Wiesel A, Schlaefer K, Spranger J. Malformations in newborn: results based on 30940 infants and fetuses from the Mainz congenital birth defect monitoring system (1990-1998). Arch Gynecol Obstet. 2002;266(3):163-167.

57. Hoevenaren IA, de Vries LC, Rijnders RJP, Lotgering FK. Delivery of healthy babies after natalizumab use for multiple sclerosis: a report of two cases. Acta Neurol Scand. 2011;123(6):430-433.

58. Hellwig K, Haghikia A, Gold R. Pregnancy and natalizumab: results of an observational study in 35 accidental pregnancies during natalizumab treatment. Mult Scler. 2011;17(8):958-963.

59. Bayas A, Penzien J, Hellwig K. Accidental natalizumab administration to the third trimester of pregnancy in an adolescent patient with multiple sclerosis. Acta Neurol Scand. 2011;124(4):290-292.

60. Fagius J, Burman J. Normal outcome of pregnancy with ongoing treatment with natalizumab. Acta Neurol Scand. 2014;129(6):e27-e29.

61. Schneider H, Weber CE, Hellwig K, Schroten H, Tenenbaum T. Natalizumab treatment during pregnancy - effects on the neonatal immune system. Acta Neurol Scand. 2013;127(1):e1-e4.

62. Martinelli V, Colombo B, Dalla Costa G, et al. Recurrent diseaseactivity rebound in a patient with multiple sclerosis after natalizumab discontinuations for pregnancy planning. Mult Scler. June 17, 2013. [Epub ahead of print.]

63. Kappos L, Radue EW, O’Connor P, et al. A placebo-controlled trial of oral fingolimod in relapsing multiple sclerosis. $N$ Engl J Med. 2010;362(5):387-401.

64. Geissbühler Y, Butzkueven H, Hernández-Diaz S, et al. Pregnancy outcomes from fingolimod clinical trials and post-marketing experience and the need for a multinational Gilenya ${ }^{\mathrm{TM}}$ (fingolimod) Pregnancy Exposure Registry in Multiple Sclerosis. Abstract presented at the 28th Congress of the European Committee for Treatment and Research in Multiple Sclerosis, Lyon, France, October 10-13, 2012.

65. Karlsson G, Francis G, Koren G, et al. Pregnancy outcomes in the clinical development program of fingolimod in multiple sclerosis. Neurology. 2014;82(8):674-680.

66. Hartung H-P, Gonsette R, König N, et al. Mitoxantrone in progressive multiple sclerosis: a placebo-controlled, double-blind, randomised, multicentre trial. Lancet. 2002;360(9350):2018-2025.

67. De Santis M, Straface G, Cavaliere AF, Rosati P, Batocchi AP, Caruso A. The first case of mitoxantrone exposure in early pregnancy. Neurotoxicology. 2007;28(3):696-697.

68. Hellwig K, Schimrigk S, Chan A, Epplen J, Gold R. A newborn with Pierre Robin sequence after preconceptional mitoxantrone exposure of a female with multiple sclerosis. J Neurol Sci. 2011;307(1-2):164-165.

69. O’Connor P, Wolinsky JS, Confavreux C, et al. Randomized trial of oral teriflunomide for relapsing multiple sclerosis. $N$ Engl J Med. 2011;365(14):1293-1303.

70. Chambers CD, Johnson DL, Robinson LK, et al. Birth outcomes in women who have taken leflunomide during pregnancy. Arthritis Rheum. 2010;62(5):1494-1503.

71. Jung Henson L, Benamor M, Truffinet P, Kieseier B. Updated pregnancy outcomes in patients and partners of patients in the Teriflunomide Clinical Trial Program. Abstract presented at the 66th Annual Meeting of the American Academy of Neurology, Philadelphia, PA, USA, April 26, 2014.

72. Gold R, Phillips T, Havrdova E, et al. BG-12 (dimethyl fumarate) and pregnancy: preclinical and clinical data from the clinical development program. In: Proceedings of the 65th Annual Meeting of the American Academy of Neurology, San Diego,CA, USA, March 16-23, 2013.

73. Cohen JA, Coles AJ, Arnold DL, et al. Alemtuzumab versus interferon beta $1 \mathrm{a}$ as first-line treatment for patients with relapsing-remitting multiple sclerosis: a randomised controlled phase 3 trial. Lancet. 2012;380(9856):1819-1828. 
74. Coles AJ, Twyman CL, Arnold DL, et al. Alemtuzumab for patients with relapsing multiple sclerosis after disease-modifying therapy: a randomised controlled phase 3 trial. Lancet. 2012;380(9856): 1829-1839.

75. Langer-Gould A, Huang SM, Gupta R, et al. Exclusive breastfeeding and the risk of postpartum relapses in women with multiple sclerosis. Arch Neurol. 2009;66(8):958-963.

76. Haas J, Hommes OR. A dose comparison study of IVIG in postpartum relapsing-remitting multiple sclerosis. Mult Scler. 2007;13(7): 900-908.

77. Hellwig K, Haghikia A, Agne H, Beste C, Gold R. Protective effect of breastfeeding in postpartum relapse rate of mothers with multiple sclerosis. Arch Neurol. 2009;66(12):1580-1581.

78. Portaccio E, Ghezzi A, Hakiki B, et al. Breastfeeding is not related to postpartum relapses in multiple sclerosis. Neurology. 2011;77(2): $145-150$.

79. Airas L, Jalkanen A, Alanen A, Pirttilä T, Marttila RJ. Breast-feeding, postpartum and prepregnancy disease activity in multiple sclerosis. Neurology. 2010;75(5):474-476.

80. Pakpoor J, Disanto G, Lacey MV, Hellwig K, Giovannoni G, Ramagopalan SV. Breastfeeding and multiple sclerosis relapses: a meta-analysis. J Neurol. 2012;259(10):2246-2248.

81. Hale TW, Siddiqui AA, Baker TE. Transfer of interferon $\beta$-1a into human breastmilk. Breastfeed Med. 2012;7(2):123-125.

82. Hellwig K, Haghikia A, Gold R. Parenthood and immunomodulation in patients with multiple sclerosis. J Neurol. 2010;257(4): $580-583$.
83. Lu E, Zhu F, Zhao Y, et al. Birth outcomes of pregnancies fathered by men with multiple sclerosis. Mult Scler. February 5, 2014. [Epub ahead of print.]

84. Boskovic R, Wide R, Wolpin J, Bauer DJ, Koren G. The reproductive effects of beta interferon therapy in pregnancy: a longitudinal cohort. Neurology. 2005;65(6):807-811.

85. Sandberg-Wollheim M, Frank D, Goodwin TM, et al. Pregnancy outcomes during treatment with interferon beta-1a in patients with multiple sclerosis. Neurology. 2005;65(6):802-806.

86. Patti F, Cavallaro T, Lo Fermo S, et al. Is in utero early-exposure to interferon beta a risk factor for pregnancy outcomes in multiple sclerosis? J Neurol. 2008;255(8):1250-1253.

87. Hellwig K, Agne H, Gold R. Interferon beta, birth weight and pregnancy in multiple sclerosis. J Neurol. 2009;256(5):830-831.

88. Amato MP, Portaccio E, Ghezzi A, et al. Pregnancy and fetal outcomes after interferon- $\beta$ exposure in multiple sclerosis. Neurology. 2010;75(20):1794-1802.

89. Coyle PK, Roberts S, Scheuerle A, et al. The Betaseron (Interferon Beta-1b) Pregnancy Registry. Int J MS Care. 2010;12 Suppl 1: 26-28.

90. Sandberg-Wollheim M, Alteri E, Moraga MS, Kornmann G. Pregnancy outcomes in multiple sclerosis following subcutaneous interferon beta-1a therapy. Mult Scler. 2011;17(4):423-430.

91. Richman S, Wallace K, Liu S, Sperling B. Final results from the AVONEX(R) (Intramuscular Interferon Beta-1a) Pregnancy Exposure Registry (P06.191). Presented at the American Academy of Neurology, New Orleans, LA, USA, April 21-28, 2012.
Degenerative Neurological and Neuromuscular Disease

\section{Publish your work in this journal}

Degenerative Neurological and Neuromuscular Disease is an international, peer-reviewed, open access journal focusing on research into degenerative neurological and neuromuscular disease, identification of therapeutic targets and the optimal use of preventative and integrated treatment interventions to achieve improved outcomes, enhanced

\section{Dovepress}

survival and quality of life for the patient. The manuscript management system is completely online and includes a very quick and fair peer-review system. Visit http://www.dovepress.com/testimonials.php to read real quotes from published authors. 